\title{
Rheological Study on Solid Structure in Colloidal Systems
}

\author{
Takayoshi Matsumoto* \\ Department of Polymer Chemistry, Kyoto University, \\ Kyoto 606, Japan
}

Solid structure in colloidal systems can be roughly classified into two groups. One is the structure which is attributed to a random aggregation of the disperse particles, the other is the ordered structure due to a regular arrangement of the particles. For these types of structure, flow and large deformation are due to a slip in some plain at a constant stress which corresponds to the yield stress $\sigma_{\mathrm{y}}$ or the absolute value of the complex stress $\left|\sigma^{*}\right|$. The value of $\sigma_{\mathrm{y}}$ is nearly equal to $\left|\sigma^{*}\right|$ at long time scale region. That is, the Cox-Merz empirical rule $\left(\sigma=\left|G^{*}\right|\right.$ at $\left.\dot{\gamma}=\omega\right)$ cannot be applied for the deformation of the structure.

Key words: Colloid / Solid structure / Yield stress / Cox-Merz rule

\section{コロイド分散系の固体構造に関するレオロジー的考察}

\author{
松本孝芳*
}

（原稿受理：1991年1月14日）

\section{1. 緒言}

コロイド分散系の固体構造とは, レオロジー的には降伏值ある いは弾性特性で特徴付けられる構造で, 概略次の二つに分類され る.一つは分散粒子の不規則凝集による構造, 他は規則的配列構 造，いわゆる結晶構造である．前者は多くの分散系にみられるが， 後者は分散粒子の形状，大きさ等の均質な系（あるいはとの混合 系）で，かつイオン強度の極端に少ない脱塩状態に执いて観察さ れる ${ }^{1) ~ 6)}$ ．これは分散粒子を取巻く電気二重層の厚さ (Debye 長 で近似される)が，脱塩とともに広がるためと考えられている6),7). このような規則構造をもつコロイドの希薄系に和ける研究は多い

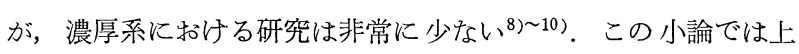
記二種類の固体構造の变形様式について, レオロジー的観点から 考察する.

\section{2. 実験}

ここで報告するコロイド系は，主にポリスチレン粒子（粒子直 径 109nm)/水系 (DIB22), 及びポリスチレン粒子 (110nm)/DEP 系 (H101) 及び感光性粒子分散系 (P730) である. DIB22 は大 きさの均質な粒子の分散系である。また，多くは円錐一円板型口 イセンベルグレオゴニオメータ (Sangamo Controls, R18, 円錐

* 京都大学工学部高分子化学教室 $\overline{\mathbf{T}} 606$ 京都市左京区吉田本町
半径 $3.5 \mathrm{~cm}$, 円錐角 1.77 度) による測定データである.

\section{3. 結果と考察}

Fig. 1 には, ポリスチレン粒子/水系 DIB22 の $12.5 \mathrm{vol} \%$ 分 散系の添加塩 $(\mathrm{NaCl})$ 濃度 $0 \sim 1365 \mu \mathrm{M}$ に扣けるせ九断応力 $\sigma$ と,

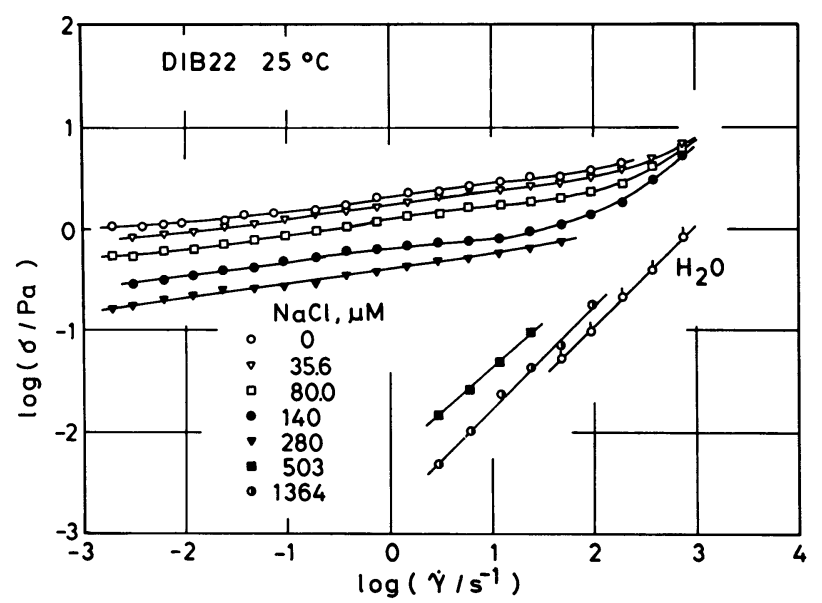

Fig. 1 Shear stress plotted against shear rate for the disperse system DIB22 at various concentrations of added salt. 
せん断速度 $\dot{\gamma}$ の関係 (流動曲線) を示す ${ }^{10}$. 添加塩濃度が $280 \mu \mathrm{M}$ 程度までは，流動曲線は低せん断速度領域で平坦になり，系は見 掛け上降伏值 $\sigma_{\mathrm{y}}$ を示す。乙かし，それ以上の添加塩濃度では突 然ニュートン流動を示すようになる. 動的弾性率 $G^{\prime}$ 及び動的損 失 $G^{\prime \prime}$ の角周波数 $\omega$ 依存性についても同様のことが言える。この 系は添加塩 $280 \mu \mathrm{M}$ 以下では明白な iridescence（虹彩色）を示 し, それ以上の添加塩濃度では白濁する.これは系内の粒子が規 則的配列状態から無秩序状態へ転移するためである. Fig. 1 に 示す非ニュートンーニュートン転移も, この秩序一無秩序転移に対 応しているとみなせる。この転移には電気二重層の厚さが重要で あると考えられている（この点関する詳しい解析は，文献 10） 参照).

これらの系の動的剛性率 $G^{\prime}$ 及び動的損失 $G^{\prime \prime}$ の 周波数依存性 曲線は, 歪 $\gamma$ が増加しても（少くとも $\gamma=0.4$ 程度までは）周波 数軸にほぽ平坦のままである。これは歪が増加しても系の秩序構 造は保たれることを意味する．Fig. 2 には，DIB22（NaCl 80 $\mu \mathrm{M})$ 飞和ける $G^{\prime},\left|G^{*}\right|,\left|\sigma^{*}\right|\left(=\left|G^{*}\right| \gamma\right)$ の $\gamma$ 依存性を示す.

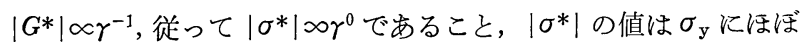
一致すること， $\left|G^{*}\right|$ と $G^{\prime}$ の差は $\gamma$ の增加とともに増加する（r の増加とともに $G^{\prime \prime}$ の寄与が大きくなる）こと等がわかる。 また， 図には Fig. 1 より求めた降伏值 $\sigma_{\mathrm{y}}$ の值も示す. $\left|\sigma^{*}\right|$ と的 は ほぼ一致する。即ち、コロイド系は降伏值とほ涪等しい一定応力 のもとに変形していることが予想される。

一般に均質高分子液体では，Cox-Merz の経験則が成立すると 考えられている.Fig. 3 にはブチルゴム溶液 $(\mathrm{EB} 70)^{11)}$, 及びポ リスチレン溶液 (L48-KC4) ${ }^{12}$ ) の $\gamma=0.1$ に拈ける $\sigma$ - $\omega$ の関係を示す． $\dot{\gamma}=\omega$ としたとき，両者は流動領域からゴム 状平坦部の広いタイムスケールにわたってよく一致する。一方, 分散系では低周波数のニュートン領域を除いて線形, 非線形にか かわらず, Cox-Merz の経験則は適用できない.Fig. 4 にはポリ

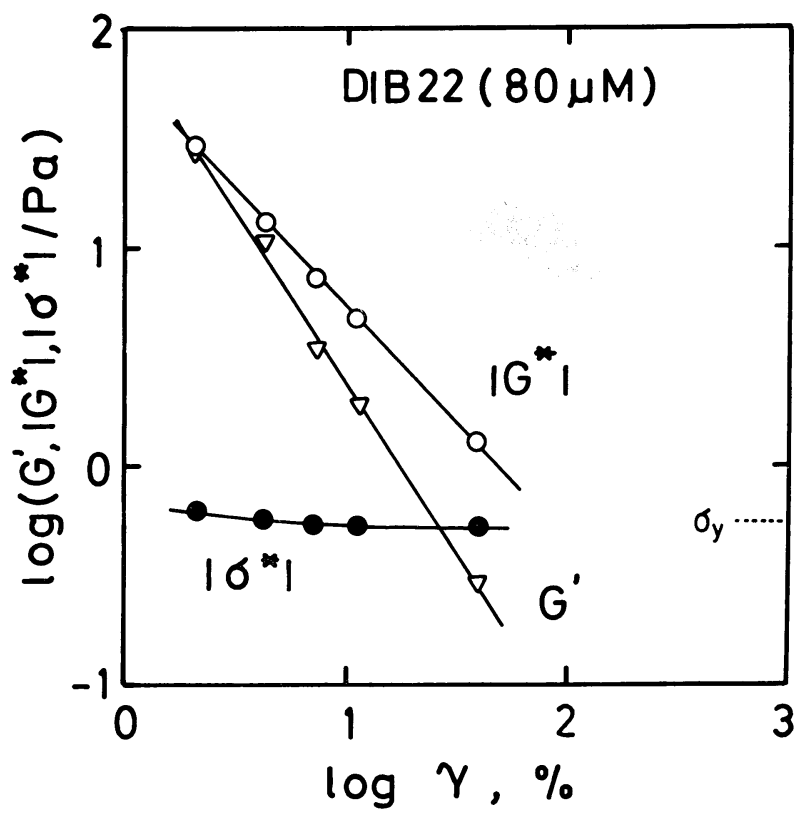

Fig. 2 Viscoelastic functions $G^{\prime},\left|G^{*}\right|$, and $\left|\sigma^{*}\right|$ at $\omega=1 \mathrm{~s}^{-1}$ plotted against the strain amplitude for DIB22 at a salt concentration of $80 \mu \mathrm{M}$.

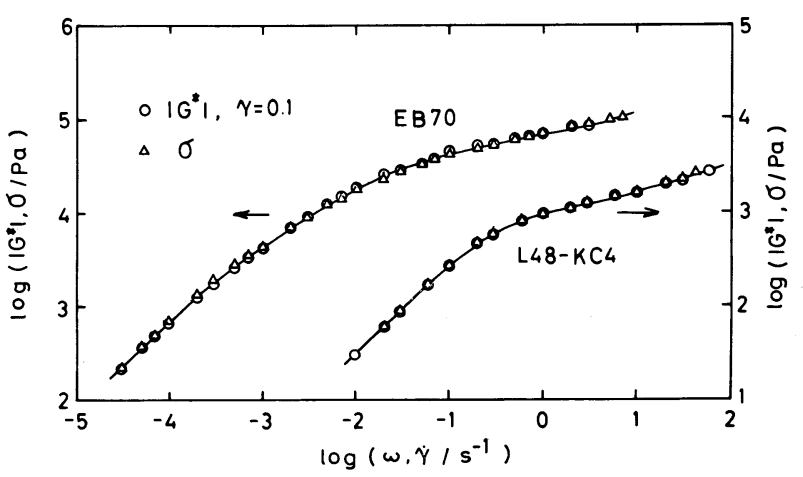

Fig. 3 Comparison between $\sigma$ vs $\dot{\gamma}$ and $\left|G^{*}\right|$ vs $\omega$ at $\dot{\gamma}=\omega$ for polymer solutions. (The data for L48 $-\mathrm{KC} 4$ are cited from the paper of Takahashi, Masuda and Onogi ${ }^{12}$ )

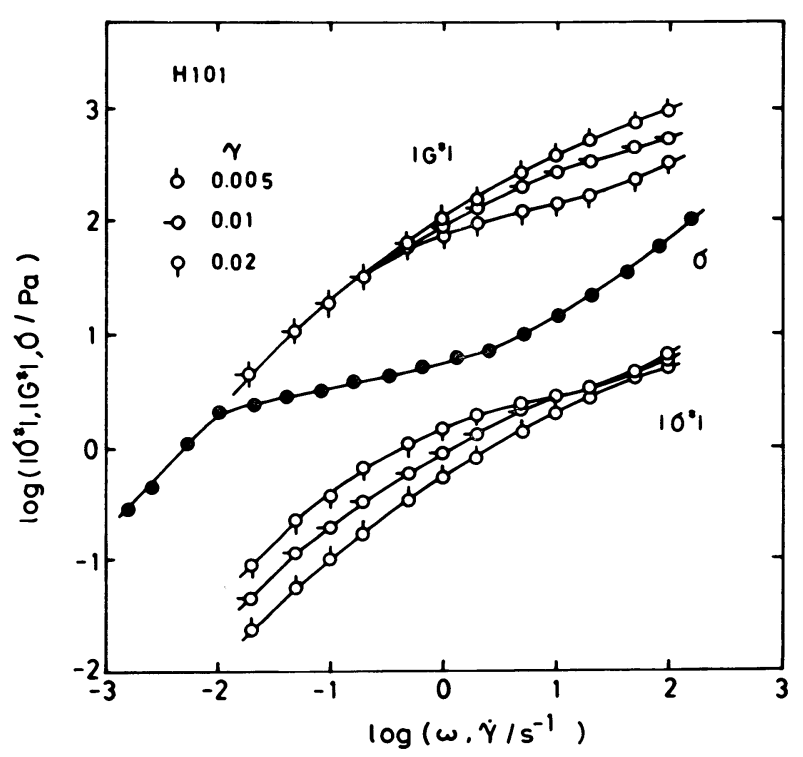

Fig. 4 Logarithmic relations of $\left|G^{*}\right|,\left|\sigma^{*}\right|$ vs $\omega$ and $\sigma$ vs $\dot{\gamma}$ for the disperse system H101.

スチレン粒子/ポリスチレン溶液系 (H101) の $\left|G^{*}\right|,\left|\sigma^{*}\right|-\omega$, $\sigma$ - の関係を示す ${ }^{13)}$. この系では分散粒子は無秩序凝集状態に あると考兄られる， $\gamma=0.05$ ではほぼ線形性を示すと思われるが， 低周波数側ニュートン領域を除いて $\left|G^{*}\right|$ と宁は大きく異なる. しかし, $\left|\sigma^{*}\right|$ の平坦部は $\gamma$ に依存しないとともに $\sigma$ の平坦部と ほ医等しい。

Fig. 5 には, 感光性粒子分散系の $\gamma=0.1$ に护ける同様のデー タを示す．この分散系では光照射によって粒子凝集が進み，液体 的挙動から降伏值を示す挙動へと変化する ${ }^{14)}$. 曲線近くの数字 1 〜 5 は，それぞれ光照射 $0,1,3,6,16$ 時間に相当する. 曲線 1 (未照射系) では， $\sigma$ と $\left|G^{*}\right|$ が特に長時間側でほぼ一致する. しかし, 凝集が進むにつれて（曲線 $1 \rightarrow 5$ ） $\sigma$ と $\left|\sigma^{*}\right|$ が一致す るようになる。

均質高分子液体系の応力緩和に拈ける非線形応力の歪依存性に

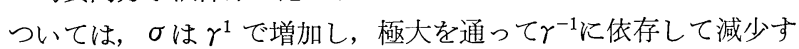
ることが，理論及び実験の両面から検証されている(15) 18). この $\sigma$ の減少は, 変形により伸長された鎖の収縮による張力の低下に 


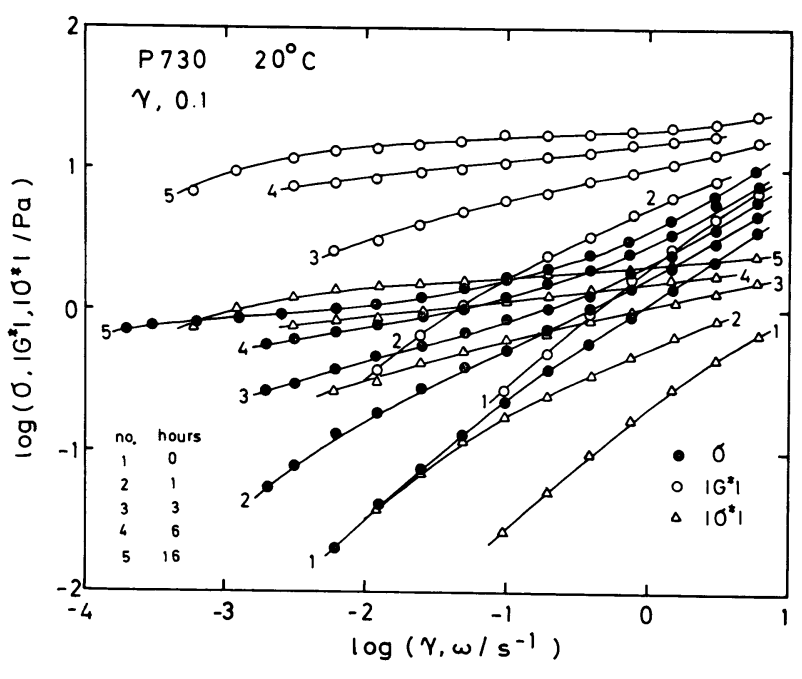

Fig. 5 Logarithmic relations of $\left|G^{*}\right|,\left|\sigma^{*}\right|$ vs $\omega$ and $\sigma$ vs $\dot{\gamma}$ for the disperse system of photosensitive particle P730.

起因すると説明される ${ }^{15)}$. 分散系ではこのような変形機構は考兄 難いし， $\left|\sigma^{*}\right|=$ 二定になる歪範囲が比較的広いことから，次の ことが予想される，即ち，秩序構造に括いては，大変形でも規則 構造が保持されることから結晶格子間の滑り, 無秩序構造では粒 子間あるいは凝集粒子間の滑りに関連した一定応力で变形が起こ るとみなせる。従って, $\left|\sigma^{*}\right|$ の一定值あるいは $\sigma_{\mathrm{y}}$ は, 秩序構造 あるいは凝集構造を保持するための粒子間（あるいは凝集粒子 間）相互作用の強さを反映しているとみなせる，それなら粒子間 相互作用の非常に弱いコロイドでは，一般的な測定のタイムスケ ールでは $\left|\sigma^{*}\right|$ の平坦部, あるいは $\sigma_{\mathrm{y}}$ は検出できないことが予 想される.この例として非イオン性ミセルコロイド（ミセル直径 約 $5.6 \mathrm{~nm})$ があげられる。これについては文献19，20）に詳しい ので詳紐は省くが, 例えばミセルが小さいためブラウン運動が激
しく,レオロジー的には規則構造として検出できないのか, ある いはミセルが非イオン性であるため, 粒子間相互作用は主に van der Waals 力に起因するため非常に弱く, 規則構造は僅かな外力 で破壊するか，あるいはレオロジー的に検出できるほどの大きさ の応力を支えることができない等が考兄れる。

\section{文献}

1) Fryling CF, J Coll Sci, 18, 713 (1963).

2) Luck W, Klier M, Wesslau H, Ber Bunsenges Phys Chem, 67, 75 (1963).

3) Hiltner PH, Krieger IM, J Phys Chem, 73, 2386 (1969).

4) Kose A, Ozaki M, Takano K, Kobayashi Y, Hachisu S, $J$ Coll Int Sci, 44, 330 (1973).

5) Ise N, Angew Chem, 98, 323 (1986).

6) Okubo T, Acc Chem Res, 21, 281 (1988).

7) Okubo T, J Chem Phys, 87, 6733 (1987).

8）美宅, 大月, 岡野, 日本レオロジー学会誌, 7, 47 (1979).

9) Matsumoto T, J Rheol, 33, 371 (1989).

10) Matsumoto T, Okubo T, J Rheol, 34, 135 (1991).

11）小野木, 升田, 松本, 日化誌, 89, 464 (1968).

12）高橋, 升田, 小野木, 日本レオロジー学会誌, 5, 72 (1977).

13) Matsumoto T, Hitomi C, Onogi S, Trans Soc Rheol, 19, 541 (1975).

14) Matsumoto T, Yao S, Onogi S, J Rheol, 29, 177 (1985).

15）土井, 日本レオロジー学会誌, 12, 33 (1984).

16）尾崎, 日本レオロジー学会誌，12，22（1984）.

17）高橋, 多久, 升田, 日本レオロジー学会誌, 18, 19 (1990).

18) Larson RG, J Rheol, 29, 823 (1985).

19) Matsumoto T, Zenkoh H, Coll. Polym. Sci, 268, 536 (1990).

20）松本, 日本レオロジー学会誌, 18, 95 (1990). 